\title{
An epistemological analysis of the application of an online inquiry-based program in tourism education
}

\author{
Liwei Hsu \\ National Kaohsiung University of Hospitality and Tourism, Taiwan
}

\begin{abstract}
This paper was designed to investigate the application of an online inquiry-based program to European tourism from an epistemological perspective. Fifty tourism students $(\mathrm{n}=50)$ participated in this study and their epistemological beliefs were measured with the Epistemological Belief Scale. A set of pre-, post-, and delayed tests were utilised to assess each participant's learning outcomes. The results showed that online inquiry-based learning (IBL) did change the participants' epistemological beliefs significantly, with a large effect size (Cohen's d) of .83. However, correlation analyses indicated that the relationship between an individual's epistemological beliefs before and after the online IBL experience, and the differences of pre- and post-tests, is rather low $(\gamma=.287)$. Yet, the association between their changed epistemological beliefs and the delayed test was higher $(\gamma=.556)$. These results suggest the possible effectiveness of online IBL in helping tourism students' develop more sophisticated epistemological beliefs, which may not be able to help learners comprehend the subject matter immediately but may facilitate better long-term retention.
\end{abstract}

\section{Introduction}

The development of Information and Communication Technology (ICT) has changed the landscape of higher education (HE) worldwide (Fenouillet \& Kaplan, 2010; Dale \& Lane, 2008; Hassanien, 2006; Sahin, Balta, \& Ercan, 2010) and has facilitated the use of virtual platforms for educational purposes (Adiele \& Nwanze, 2010) through interactivity and opportunities for collaboration (Ikpeze \& Boyd, 2007). Since the tourism industry deals with massive flows of information (Buhalis, 2000), students of tourism programs are expected to be familiar with activities in the virtual environment (Kasli \& Avcikurt, 2008; Sigala, 2002). Many HE institutions thus use the Internet as the major delivery mechanism of educational content or as a complementary tool in tourism programs to enhance the effectiveness of student learning (Leung \& Ivy, 2003).

However, technology cannot create meaningful learning by itself, nor can it automatically initiate interactions (Chen \& Choi, 2010; Tsai, Tsai, \& Hwang, 2011a, 2011b). A Web-based or online learning environment entails a learning process that depends greatly on the autonomy of the learner; nevertheless, such learning has been found to easily lead students astray (Shih, Chuang, \& Hwang, 2010; Van Fossen, 2004; Scarlatos, 2006; Rogers \& Price, 2009; McLoughlin \& Lee, 2008). Guidance and regulative support from an instructor, along with meaningful content, are of great importance and assistance in overcoming this problem (Manlove, Lazonder, \& Jong de, 2009). Therefore, inquiry-based instruction has been acknowledged as an appropriate way to deliver online instruction without the aforementioned drawbacks. Easy access to information is one of the major advantages of online inquiry-based education, although the retrieved information may be inconsistent or even contradictory. In this case, the epistemological beliefs of an individual will be greatly associated with his/her Web-searching skills (Hofer, 2004), particularly when they encounter inconsistent or contradictory information (Bråten, Strømsø, \& Samuelstuen, 2005; Kienhues \& Bromme, 2011). Epistemological beliefs are defined as the beliefs of an individual concerning the nature of knowledge and the conformation or acquisition of knowledge (Chan, 2007; Tu, Shih, \& Tsai, 2008; Liu \& Liu, 2011; Hofer, 2001). Personal epistemological beliefs can be associated with an individual's learning strategies (Chan, 2003; Cakir, 2008; Tsai, 2012), which subsequently affect learning outcomes (Kizilgunes, Tekkaya, \& Sungur, 2009); these beliefs can be influenced by education (King \& Kitchener, 2004) or a teacher's pedagogy (Brownlee \& Berthelsen, 2008). Furthermore, it is considered a main task of HE to cultivate students' critical thinking ability, which goes beyond the curriculum content (Brownlee \& Berthelsen, 2008), and their epistemological beliefs should be the ground for that kind of ability (Kuhn \& Udell, 2001). Moreover, learners' epistemological beliefs also influence the way they construct and evaluate arguments (Cho, Lee, \& Jonassen, 2011). In other words, when they encounter masses of information online, their epistemological beliefs will lead them toward various directions with different cognitive and 
metacognitive activities that they have manipulated (Hofer, 2004). These factors can predict the students' academic performance (O’Siochru \& Norton, 2013).

In the present study, an inquiry-based tourism program was designed to investigate the epistemological beliefs of tourism students regarding this innovative pedagogy. The epistemological beliefs of individuals have been considered crucial to self-regulated learning (Muis, 2007), classroom-related learning outcomes (Chan \& Sachs, 2001), and the benefits they derive from Web-based instruction (Harteis, Gruber, \& Hertramph, 2010). The epistemological beliefs of tourism students are unknown concerning subject-matter learning acquired through inquiry-based instruction and learning. The goal of this article is to shed light on this underexplored topic and expand our current understanding of it. Hence, two research questions are addressed in the present study:

1. How are the beliefs of tourism students regarding the nature of knowledge and knowing the subject matter of tourism manifested within the context of online inquiry-based pedagogy and learning?

2. How are the epistemological beliefs of individuals associated with learning outcomes?

To achieve the objective of this paper, I would have to review pertinent literature on inquiry-based programs and develop the theoretical framework for the application of this type of program to tourism education, particularly within the virtual learning environment (VLE). To empirically examine the implementation of an online inquiry-based program for tourism education, a web-based course was designed and offered to a group of tourism-major students in Taiwan, who joined this project voluntarily. A survey was administered and the results were analysed to yield insights into the changes in the epistemological beliefs of the participants after they experienced the online inquiry-based program. Further, correlation analyses on the changes of epistemological beliefs and the pre-test, post-test, and delayed test results were also included to provide a comprehensive picture of the association of these variables. A discussion section provides comparative information on the results of the present study and antecedent research, after which comes the conclusion.

\section{Online learning modalities}

\section{Rationale of the inquiry-based learning (IBL) program}

Inquiry is a natural process of exploration for knowledge construction and development, which should be guided for optimal results (Chan, Lam, Yang, Mark, \& Leung, 2010). IBL programs involve learners in exploring the contents, issues, and problems of the target area of knowledge based on research-oriented pedagogy (Lane, 2007; Jordan, 2005). Given this attribute of IBL, the roles played by instructors in online courses will differ from those of instructors in conventional courses; this innovativeness in pedagogy has been acknowledged as constructivist learning (Hmelo-Silver, Duncan, \& Chin, 2007; Miller \& Lu, 2003). Advocates of constructivist learning postulate that learning should be triggered when learners' existing knowledge is blended with new information to construct new knowledge. Therefore, learners are able to generate new knowledge while interacting with their instructor, peers, and environment (Garcia, Pacheco, \& Garcia, 2010). This model of knowledge construction was derived from the rationale of the individual's social collectivity in the learning process, as proposed by Vygotsky (1978) and Liu \& Matthews (2005). Constructivist learning lays heavy emphasis on learners' self-reflection on learning and collaboration between peers (Peterson, 2006); such paradigms have been widely welcomed by practitioners (Gulati, 2004). As Savery and Duffy (2001) suggested, "The teacher's role should be to challenge the learner's thinking - not to dictate or attempt to proceduralise that thinking" (p. 5). Further, the teacher should contextualise the learning situation in a real-life setting while the students are engaged in exploration ( $\mathrm{Li}$ \& Lim, 2008; Chen \& Chen 2012). The pedagogical competence of the teacher in supporting IBL and helping students fulfil inquiry tasks fosters the practice of such instruction (Lakkala, Lallimo, \& Hakkarainen, 2005). Such constructive forms of teaching and learning have also gradually transformed the landscape of hospitality and tourism education, which warrant more studies to explore potential discrepancies in the relevant conceptions of stakeholders (Zwaal \& Otting, 2006). Epistemological beliefs are part of said conceptions.

The results of empirical studies (Hickey, Wolfe, \& Kindfeld, 2000; Lynch, Kuipers, Pyke, \& Szesze, 2005; Prince \& Felder, 2006; Shih, Chuang, \& Hwang, 2010) affirmatively demonstrate the advantages of 
IBL toward learning effectiveness and the resultant long-lasting retention of information (Bilgin, 2009). Further, cases reflecting the great success of web-based or collaborative-technology IBL have been reported in academic studies (Rogers \& Swan, 2004; Hakkarainen, 2003). IBL's success may be attributed to the iterative process, which leads learners to acquire and further enhance their metacognition regarding subject-specific knowledge (Tan \& Chan, 2008). Metacognition, as defined by Hofer (2001), is indicated by the present study as an individual's knowledge about knowing and his or her control over cognitive activities. Therefore, within such iterative processes, the epistemological beliefs of an individual are assumed to become associated with his or her engagement in rational inquiry (Valanides \& Angeli, 2005), although little is known about the role such beliefs play in the learning process (Barzilai \& Zohar, 2012).

IBL will not naturally generate promising learning outcomes; some studies have raised the possibility of hindrances when IBL is applied. Wu and Hsieh (2006) pointed out some potential challenges that instructors may encounter in IBL, which mainly stem from the students' lack of interest in engaging in the inquiry process. Oliver (2007) also indicated concern about the relevance of and interest generated by the materials presented to students; these were considered as a factor in persuading students to engage in the inquiry process. Regarding the administration of IBL on the Internet, Lim (2004) stressed the importance of designing interesting contents to encourage participation in the tasks and add scaffolding to the learners' knowledge. These studies share the same standpoint, namely, that the most prominent challenge to IBL is convincing students to engage in the inquiry process through interesting materials and/or contents. If the students see the contents as relevant and interesting, they will be encouraged to try IBL, as prior research suggests. This possibility, however, requires more empirical evidence. Further, none of the antecedent cases specifically explored the applicability of online IBL to tourism education, nor did they analyse this issue from an epistemological perspective. To fill the gap in academia, the present study aims to orchestrate a pilot course to explore the unanswered research questions.

\section{Tourism education within the virtual learning environment}

An increasing number of tourism and hospitality programs are being offered online partially (i.e. webassisted courses) or exclusively (i.e. web-only courses) (Leung \& Ivy, 2003). Numerous studies have tackled the pros and cons of VLE in tourism education. For example, in a study conducted by Hassanien (2006), the participants, who were students in a Leisure, Tourism, and Hospitality program, expressed positive attitudes toward learning research methodology via WebQuest, an online application. On the basis of this solid evidence, the author further argued that the primary job of a university lecturer is to help students achieve optimal learning results through technology-based strategies.

Modern technology has been regarded as an effective means of promoting learning, particularly in facilitating self-directed and lifelong education (Lim, 2004). Nevertheless, certain drawbacks to online learning have been revealed; the major ones include navigational disorientation, information overload, and distraction (Bradshaw, Bishop, Gens, Miller, \& Rogers, 2002; Van Fossen, 2004). IBL seems to be the solution to the needed guidance of a tutor, as it enables independent learning and critical-thinking ability among learners, thereby maximising the effectiveness of online learning. The abilities to rapidly acquire new knowledge and think analytically are major generic competencies for tourism graduates (Munar \& Montaño, 2009) that can be cultivated with the administration of IBL. What remains to be investigated is the integration of ICT and IBL in the tourism program. The results of the present study ought to be able to answer the relevant questions empirically.

\section{Online inquiry-based program in tourism education}

Tourism curricula tend to be criticised as being directed toward specific occupational skills (Inui, Wheeler, \& Lankford, 2006). "Questions of meaning" and a "reflective philosophical method" are necessary for renovating tourism curricula, as Tribe (2001) advocated. The Sustainable Tourism and the Environment Program (STEP), implemented at the University of Northern Iowa, offers training in research-oriented skills, which include "formulating researchable questions, gathering data and analysing results" (Inui, Wheeler, \& Lankford, 2006, p. 28). Well-designed online IBL programs can be valuable venues that trigger the use of cognitive tools among learners as well as provide procedural guidance for inquiries, whereas a constructive learning community for solving complex problems can be established based on the interactions (Slotta, 2002, cited in Lim, 2004). According to Lim (2004), online IBL has the following 
benefits in teaching and learning:

- Encourages participation in learning tasks

- Provides learners with extensive opportunities to collaborate

- Enhances learning with more self-directed activities

- increases the involvement of learners in the learning process

Further, tourism is an industry with weighty context-aware applications (Paganelli, Bianchi, \& Melani, 2006) requiring important contextual information on culture, geography, history, and language to meet the needs of tourists (Tan \& Chan, 2008). As Cushner (2004) postulated in his book, Beyond Tourism, the complexity of social reality can be learned best in a context that "enables learners to participate in the social milieu of the host setting" (p. 119). Travelling and staying in the community of the target culture is the best way to experience such learning, although cost is a crucial consideration. IBL seems to be an alternative that can accomplish the aims and goals of the meaningful understanding of other cultures (Minick \& Bocchicchio, 2006) because it enables learners to situate learning in investigating complex tasks. Thus, IBL facilitates deep and meaningful learning (Wu \& Hsieh, 2006).

Therefore, it is logical to hypothesise that IBL is an ideal approach for learners to achieve "deep learning" of complex topics such as tourism, especially when the activities are conducted online, where vast amounts of information can be retrieved in little time. This is a major advantage of online IBL over IBL undertaken in conventional settings. The process of inquiry on various websites demands the learner's cognitive and metacognitive awareness to retrieve useful information (Wegner, Holloway, \& Garton, 1999); students usually do not activate metacognitive thinking unless they are explicitly advised to do so through related activities (Lin, 2001). In this process, learners can successfully complete online inquiry tasks when aided by instructional scaffolding from the teacher and can further acquire solid knowledge of the subject matter (Li \& Lim, 2008). Since online IBL has been advocated to prompt the aforementioned advantages to learning, it is hypothesised in the present study that this pedagogy triggers deep learning among tourism students. The present study aims to provide empirical evidence of this issue and acquire new ideas about argument. In other words, the first research question aims to find out whether online IBL is capable of arousing sophisticated epistemological beliefs among tourism students toward learning the subject matter. However, the answer would be pointless if there is no association between sophisticated epistemological beliefs and learning outcomes. Therefore, the second research question ponders the relationship between these two variables. Previous research on how one's epistemological beliefs intertwine with learning outcomes or academic performance is featured in the following section.

\section{Epistemological beliefs}

Research on epistemological beliefs in the literature can be traced back to the work of Perry in the 1960s (Zwaal \& Otting, 2007). The developments and changes in the epistemological beliefs among learners had already attracted the interest of researchers at that time (Pintrich, 2002; Brăten \& Strømsø, 2006). Epistemological beliefs, which were defined by Hofer (2004) as students' views of learning and the nature and construction of knowledge, have been extensively studied by researchers in web-based and traditional face-to-face settings (Schraw \& Sinatra, 2004; Valanides \& Angeli, 2005; Malaki, 2009; Conley, Pintrich, Vekiri, \& Harrison, 2004; Briell, Elen, Depaepe, \& Calrebout, 2010). It has been plausibly asserted that the epistemological beliefs of learners are associated with academic performance (Hofer, 2001; Muis, 2007; Schommer-Aikins, Duell, \& Hutter, 2005; Lodewyk, 2007; Peng \& Fitzgerald, 2006; Bendixen \& Hartley, 2003) and critical-thinking skills (Valanides \& Angeli, 2005; Chan, Ho, \& Ku, 2011). The reason may be that learners with sophisticated epistemological beliefs have an intrinsic motivation to achieve high self-efficacy in the subject matter (Rozendaal, Brabander, \& Minnaert, 2001). Learners with sophisticated epistemological beliefs tend to realise that knowledge is uncertain and changeable; consequently, they use various learning strategies and/or cognitive processes to acquire different types of new information (Pieschl, Stahl, \& Bromme, 2008). In contrast to their counterparts who have naïve epistemological beliefs, they have flexibility and adaptability in the learning process, which helps them fit into contextual demands (Elby \& Hammer, 2001). Therefore, teachers should pay sufficient attention to the development of learners' epistemological beliefs (Zwaal \& Otting, 2006). The aforementioned studies pointed out the advantages of having sophisticated epistemological beliefs toward learning outcomes, and scholars such as Rodríguez and Cano (2006) have argued that a person's epistemological beliefs are not innate and thus can be changed by the education that they receive. It is interesting to explore how tourism students' epistemological beliefs are influenced by the innovative 
pedagogy of online IBL.

Concerning the epistemological beliefs of learners in a web-based context, Chuang and Tsai (2005), Tsai (2008), and Tsai, Tsai, and Hwang (2011a) postulated that students and teachers tend to have more advanced (or sophisticated) epistemological beliefs when instruction takes place online rather than in the traditional face-to-face format. Therefore, designers and instructors of web-based courses should be aware of the epistemological beliefs of learners before the beginning of the course (Zwaal \& Otting, 2007). In light of epistemological beliefs and online IBL, the composition of web-based courses tends to be even more complex than other modalities of web-based learning because web searching is considered a complicated cognitive procedure (Tu et al., 2008). For example, a study conducted by Mason, Boldrin, \& Ariasi (2010) described a situation in which, when asked to retrieve information online, learners with sophisticated epistemological beliefs would justify the authenticity of information from multiple sources, whereas learners with naïve epistemological beliefs would rely on only one source of information. According to Paavola, Lipponen, and Hakkarainen (2002), in addition to the knowledge of technical and social infrastructure in implementing online IBL, epistemological infrastructure plays an important role in the manifestation of such programs. Moreover, the results of studies conducted by Tsai, Tsai, and Hwang (2011a) and Whitmire $(2003,2004)$ showed that the epistemological beliefs of individuals were related to their online searching strategies.

However, research by Tsai (2008) explored the relationship between epistemological beliefs and contextual factors from another perspective; he used online IBL as the instructional paradigm to teach science to Taiwanese high school students. The results of his study stated that online IBL facilitates the sophistication of epistemological beliefs. However, a study conducted by Harteis et al., (2010) denied the influence of the epistemological beliefs of learners on the quality and quantity of e-learning. Additionally, the issue of whether the epistemological beliefs of an individual are developmental or influenced by instruction, and whether learning through ICT affects the epistemological beliefs of learners remains debatable (Valanides \& Angeli, 2005). The developmental model of epistemological beliefs proposes that the epistemological beliefs of an individual change-following a specific pattern - as the cognitive development of that individual evolves (Hofer, 2001). In a similar vein, Hammer \& Elby (2002) argued that epistemological beliefs are context-specific and play different roles in different disciplines. However, none of these aforementioned studies has used the subject of tourism as the educational context for research. It is plausible to state that the relationship between the epistemological beliefs of a learner and online learning is still controversial; including contexts wherein online IBL is applied to tourism education. The present study attempts to explore this underdeveloped topic in tourism education and provides the results of the empirical examination of this controversy.

\section{Materials and methods}

\section{Context of the present study}

This study was based on a tourism course on European cultures offered to sophomores enrolled in the Travel Management Department of National Kaohsiung University of Hospitality and Tourism, Taiwan. The purpose of this course is to familiarise students with knowledge concerning the culture, geography, history, and languages of major European countries; it specifically refers to relevant information that a professional tour leader is supposed to acquire to fulfil his/her duties. In the present study, the course was adapted into an online format for learners who wanted to review or enhance their understanding of such subject matter. Since these students were at the elementary level of professional training in tourism and we wanted to broaden their thinking ability rather than merely funnel their responses into preprogrammed professional modes, online IBL was designed to fit the goal of this program.

According to Shih, Chuang, and Hwang (2010), four approaches can be adopted in the inquiry-based program: structured inquiry, guided inquiry, open inquiry, and learning cycles. For practical uses, open inquiry and guided inquiry are the most widely applied approaches (Bilgin, 2009). As Rop (2002) pointed out, regardless of the advantages that it contributes to academic achievement, the open inquiry approach is more intellectually challenging to learners and also leads to more problems for the teacher conducting the inquiry activities. Therefore, in the present study, we adopted guided inquiry as the major concept for designing the tasks. 
The challenges facing the instructor who implements IBL have been addressed by Edelson, Gordin, and Pea (1999) and Lim (2004). Five challenges have been identified that relate to the character of individual learners:

1. Intensity of motivation (because the extended nature of IBL requires strong motivation from learners to support learning).

2. Familiarity with and access to investigation techniques, such as data collection and analysis (because these skills require certain levels of precision and care).

3. Background knowledge (because all the research-oriented tasks require learners to have a basic understanding of the target contents to be able to accomplish meaningful investigations).

4. Ability to manage extended activities (e.g. open-ended inquiries, which are much more complicated than conventional ones).

5. Practical constraints to creating learning context, especially because the technologies are embedded in the course design (i.e. if learners have difficulty accessing the Internet, they may not be able to fulfil the designed tasks).

Given the acknowledged challenges, consideration should be given to learning needs in the design of the curriculum and technology. First, all the participants joined this program voluntarily, thus naturally excluding learners without commitment or strong motivation from the study. Regarding the second concern, an orientation session on the VLE was held for all participants before the commencement of the course to ensure their familiarity with and access to the investigation technique. Each learner was assigned a username and password that they could change after the first login. Additionally, since all the participants had passed the prerequisite courses on European tourism, they had a certain level of background knowledge about the contents of the new course. Further, they all had taken a research methodology course before enrolling in this program. Last, access to the Internet was ensured to help learners accomplish the inquiry-based tasks.

The program comprised five collective and/or individual tasks, all of which involved open-ended questions that were designed in consultation with the teacher of the European Tourism course. Each session for every task lasted approximately 60 minutes. The progressive inquiry model adopted for the starting point of the process was constructed based on actual questions from the students and their existent knowledge. The mechanisms of explanations and feedback from the teacher served as the foundation for the scaffolding of new knowledge through ICT (Lakkala, Lallimo, \& Hakkarainen, 2005; Tan \& Chan, 2008). For example, in one of the tasks, the students had to design a 12-day travel package from Taiwan to Austria and the Czech Republic, with a budget of approximately USD 2,500. They had to search online for the best deals in airfares and accommodation. They also needed to decide what places their customers would visit and explain why they selected these places. The instructor was online to answer their questions and raised questions about the trip when necessary.

To ensure the flow of the online IBL that was designed for the present study, WebQuest software was adopted for administering the learning activities. The framework of the course design was established by the author of this study in accordance with the designs of Chang, Chen, and Hsu (2011), which aimed to provide students opportunities to discover and explore information for knowledge construction through inquiry-oriented activities. Internet was the major information source and students were expected to finish tasks with the information retrieved online.

\section{Participants}

The participants $(N=50 ; 32$ women, 18 men $)$ in the present study were tourism major students of National Kaohsiung University of Tourism and Hospitality. Their ages ranged from 20 to 25 years (mean $=22.52, S D=1.67$ ). To a certain extent, they represent typical tourism major students in Taiwan. All voluntarily partook of this program in their spare time, and no remuneration was offered. Further, the purpose of this study was explained to them and they were assured of anonymity regarding their test performance and scale responses that measured their epistemological beliefs. Prior studies (Chan, 2003; Chan \& Elliot, 2003; Conley, Pintrich, Vekiri, \& Harrison, 2004; Schommer-Aikins, 2004; Youn, 2000) have elucidated that individual epistemological belief systems differ due to the cultural background; therefore, it is noted that the present study emphasised the cultural specification of the epistemological belief system, which focused on learners with a Confucian-heritage culture background. 


\section{Measurement of epistemological beliefs}

To address the research questions, an epistemological scale measuring guided IBL was selected for administering to the participants at the end of the program. Inevitably, certain limitations have been recognised in the use of self-report questionnaires to measure epistemological beliefs (Teo \& Chai, 2011). Thus, researchers have to exercise special caution when choosing appropriate instruments to administer measurement. Many inventories (e.g. the Schommer Epistemological Questionnaire; the 26-item instrument developed by Elder, 2002; interview questions by King \& Kitchener, 2004; and the Epistemic Beliefs Inventory by Schraw, Bendixen, \& Dunkle, 2002) have been developed, as Duell and SchommerAikins (2001) point out in their investigation of the epistemological beliefs of individuals. Nevertheless, questions have arisen concerning the adequacy of these measures when applied to various research contexts. Further, Conley et al. (2004) suggested that redundancy in the measurement of epistemological beliefs should be avoided by adopting a shorter instrument that focuses on the constructs in a straightforward manner. Since there is no agreement on how to conceptualise epistemological beliefs and the self-report questionnaire is still the widely accepted instrument for the survey (Deniz, 2011), the present study adopted the Epistemological Belief Scale (EBS) constructed by Chan and Sachs (2001). The EBS was developed based on "beliefs [among learners] that knowledge is constructed and that it is related to thinking, understanding, and problem solving" (p. 195). This questionnaire has been widely utilised in previous studies on learning with ICT (e.g. Tsai \& Chuang, 2005; Tu et al., 2008; Tsai, 2012) because of its satisfactory validity and reliability in being used empirically. It was further articulated that the EBS was developed within the Asian cultural context, which prevented the occurrence of cultural bias (Tsai \& Chuang, 2005) and thus enhanced the appropriateness of applying it in the present study.

However, this scale has never been used in the field of tourism education. Despite the argument of Schommer-Aikins, Duell, \& Barker (2003) that "epistemological beliefs of college undergraduates are moderately domain general" (p. 360), it is necessary to ensure the correspondence between the subject matter under investigation and the domain mapped by the EBS to optimise its goodness of measuring the proposed construct. To achieve this goal, certain modifications were made to suit the context of the current study, which included the way question items were described and the change of subject matter (please refer to the appendix for the revised scale). Experts in tourism education (a professor of the Travel Management Department, a professor from the field of hospitality and tourism education, and a teacher of tourism program from a public high school) were invited to review the content validity of the EBS inventory being used to investigate the participants' epistemological beliefs in learning the subject matter. Despite the fact that detailed and holistic information on epistemological beliefs was difficult to retrieve with an inventory of nine items, the experts concurred that with the modifications, the EBS was suitable for measuring one aspect of the students' epistemological beliefs: the level of sophistication. The participants chose one of three options in responding to each question and gained one point if they selected constructive items. Some questions contained more than one constructive answer. In the end, each participant received a score representing the sophistication of his/her epistemological beliefs. The scores indicated the extent of flexibility and adaptability that learning strategies will have in the cognition process.

\section{Measurement of learning outcome}

Participants had not taken any courses on European tourism during the first year of their college education, and their prior knowledge was expected to vary. Students' learning outcomes were measured by 50 multiple-choice questions, which were designed using information that the participants had supplied during their tasks (i.e. their knowledge about the two destination countries, namely, Austria and the Czech Republic). Here are a couple of sample questions: "On the way from Salzburg to Prague, what is the name of the town located along the Vltava River?" and "Why was Salzburg called the "Salt Fortress'?" To enhance the validity of the research results, a post-questionnaire test was administered one week after the initial test. The average score of these two tests were assigned individually for further statistical analyses.

\section{Data collection and analysis}

Data were collected in the fall semester of the academic year 2011. The epistemological beliefs of the participants were measured using self-report questionnaires that were administered twice (at the 
beginning and after the completion of the program). The EBS was distributed to the participants via email in October and December 2011, then a follow-up e-mail message was sent to make sure they had received the questionnaire. They were given three days to finish the questionnaire and return it by e-mail. Reminders were continuously sent to those who failed to turn in the questionnaire on time until their responses were finally received.

The collected data were analysed statistically with SPSS software, version 19.0. Descriptive statistics, such as frequencies, mean scores, standard deviation $(S D)$, skewness, and kurtosis are presented, followed by a paired sample t-test and correlation analysis using the participants' EBS scores as the independent variable and their performance on the assessment as the dependent variable. Effect size is also included to measure the magnitude of the treatment effect (online IBL, in this study); this is beneficial in terms of complementing the missing content, thereby providing statistical significance for further interpretations of the results (Kotrlik \& Williams, 2003; Nakagawa \& Cuthill, 2007; Thompson, 2002). It has been postulated that reporting effect size increases the practical meaningfulness and importance of a study (Capraro \& Capraro, 2002) because statistical significance tests only reflect the probability of a particular outcome (Kirk, 2001; Olejnik \& Algina, 2000). More importantly, by including effect size in the analytical results, researchers can compare the results of different studies (Kirk, 2001; Kotrlik \& Williams, 2003; Thompson, 2002). As suggested by Kotrlik and Williams (2003), Cohen's $d$ should be used to calculate the effect size of the paired t-test, which is interpreted as small $(d<.20)$, medium $(d<.50)$, and large $(d<.80)$ (Cohen, 1988).

\section{Results}

\section{How are the beliefs of tourism students regarding the nature of knowledge and knowing the subject matter of tourism manifested within the context of online inquiry-based pedagogy and learning?}

The results of the descriptive statistics show that most tourism students in Taiwan would score 6.96 on a scale of 9.00 for epistemological beliefs before experiencing online IBL. The higher the score an individual got on the scale, the more sophisticated their beliefs were in learning European Tourism. After they had undergone online IBL, their epistemological beliefs become more sophisticated (i.e. 7.86) and universal. The data in Table 1 reflect such results empirically.

Table 1

Descriptive statistics of tourism students' changes of epistemological beliefs

\begin{tabular}{lllllll}
\hline & Mean & SD & \multicolumn{2}{c}{ Skewness } & \multicolumn{3}{c}{ Kurtosis } \\
\cline { 4 - 7 } & & & Statistic & SE & Statistic & $S E$ \\
\hline $\begin{array}{l}\text { Epistemological } \\
\text { belief 1 }\end{array}$ & 6.96 & 1.32 & -1.13 & .337 & 3.06 & .662 \\
$\begin{array}{l}\text { Epistemological } \\
\text { belief 2 }\end{array}$ & 7.86 & 0.78 & -.543 & .337 & .285 & .662 \\
\hline
\end{tabular}

The paired sample t-test was administered to examine the significance of the changes in epistemological beliefs among participants before and after they had experienced online IBL. The detailed data are presented in Table 2 .

Table 2

Paired sample test of changes of epistemological beliefs

\begin{tabular}{lllllll}
\hline Paired & $M$ & $S D$ & $S E M$ & $t$ & $d f$ & Sig. \\
\hline $\begin{array}{l}\text { Epistemological } \\
\text { Belief 1 }\end{array}$ & & & & & \\
$\begin{array}{l}\text { Epistemological } \\
\text { Belief 2 }\end{array}$ & -.9000 & 1.147 & .1622 & -5.547 & 49 & .000 \\
\hline
\end{tabular}

The increased mean scores of the students (from 6.96 to 7.86 ) attest to the advantages of online IBL: they had deepened their knowledge of the subject matter and their mastery of the process of acquiring it. The 
skewness and kurtosis statistics reflect the fact that the distribution of the epistemological beliefs of most participants is close to the mean score. The result of the administration of the paired sample t-test (as shown in Table 2) confirms that the changes in the epistemological beliefs of the students are significant $(t=-5.547, p<.001)$. For the effect size, Cohen's $d$ was .83 , indicating that the treatment effect was large (Cohen, 1988). In other words, online IBL did have a large positive effect on the sophistication of an individual's epistemological belief in learning European tourism. In addition, the positive kurtosis indicates a peaked type of distribution. Therefore, it can be concluded that the epistemological beliefs of most students were within a particular range before they experienced IBL, as the peaked distribution changed after they were instructed through IBL.

\section{How are the epistemological beliefs of individuals associated with learning outcomes?}

To address this research question properly, two correlational analyses were applied to explore the association between the sophistication of epistemological beliefs and learning outcomes of the participants related to the subject matter of tourism. The first correlation explored the association of the change in the sophistication of epistemological beliefs among individual learners and the differences in their performance between the first and second tests. The difference in the epistemological beliefs of a learner indicated the influence of IBL on their knowledge per se. However, differences in performance can measure the knowledge that each participant acquired during the course of IBL.

The results of the correlation analysis of these two variables (differences between individual participant's two epistemological beliefs and two tests) have a positive and weak coefficient $(\gamma=.287 ; \mathrm{p}=.043)$. Explicitly, the change in the epistemological beliefs of individual learners was significantly associated with the change in their learning outcomes, which indicated that the development of sophisticated epistemological beliefs positively influences one's learning outcomes and vice versa, even though the effect may not be salient.

The second correlation analysis aimed to collect in-depth data on the epistemological beliefs of participants who had experienced IBL and reveal how such beliefs were interrelated with their learning outcomes. In terms of the measurement of learning outcomes for this analysis, the scores of the delayed test administered two weeks after the last interactivity of IBL were collected. The correlation coefficient of the epistemological beliefs of participants and their performance on the delayed test showed that at the .01 level, there was a positive yet moderate relationship between these two variables $(\gamma=.556, p<.00)$. This coefficient is slightly higher than the previous one, possibly because the scores were related to ultimate epistemological beliefs stemming from the greater accountability of the retention of learning outcomes. In other words, it is safe to state that tourism students with stronger epistemological beliefs are keen on achieving better long-term learning outcomes. However, the influence of online IBL in regard to their learning could not yet be confirmed.

\section{Discussion}

After presenting the rationale for IBL, application of ICT in tourism education, and integration of ICT and IBL, an online IBL program for a tourism course was designed. The results of the present research did not directly attest to the promising benefits that online IBL may bring to student learning of the subject matter of tourism. However, online IBL is an advantageous tool, leading students to more favourable epistemological beliefs in learning about tourism, perhaps stemming from the guidance of the instructor in the inquiry process. As Van Fossen (2004) stated, "the process of finding quality information from among the millions of websites available on many topics has been likened to trying to drink from a fire hose" (p. 13). With proper guidance from the instructor, learners can have opportunities to experience activities by engaging in inquiry practice; hence, the development of their inquiry abilities would be promoted (Tsai, Tsai, \& Hwang, 2011a; Chen \& Chen, 2012). The results of the present study support an additional benefit: an improvement in tourism students' epistemological beliefs in acquiring knowledge related to European tourism. This echoes the assumption that IBL may promote epistemological development (Conley et al., 2004). However, the question whether the same positive results can be derived without the guidance of an instructor in online IBL remains unanswered.

Familiarity with ICT is of great importance to the future success of tourism students (Kasli \& Avcikurt, 2008); integrating computer or instructional technologies in pedagogy can help them acquire a working 
knowledge of computers as a by-product of constructing knowledge on the subject (Strickland, 2005). In other words, the prevalence of using ICT for learning and instruction should not be overlooked because the epistemological beliefs of individual learners influence the process and purpose of e-learning (Harteis, 2010). Further, when IBL is administered virtually, learners are able to explore a problem and its background information, as well as team up and discuss ways to solve the problem without the impediments of time and location (Chan et al., 2010). It has been hypothesised that the learning attainments of students with regard to target content excel those of their classroom counterparts if IBL can be implemented within the context of a cooperative learning environment (Bailey, 2008; Hofstein \& Lunetta, 2004; Bilgin, 2009), because meaningful learning can be initiated through the discussion of concepts among students.

However, this statement did not receive strong support in the present study, which elicited a significant yet weak association $(\gamma=.287)$ between individual epistemological beliefs and performance. The major reason for this may be the lack of backups from the teacher in implementing IBL; teachers require external technological and pedagogical support to develop their expertise and implement IBL through scaffolding, and this results from inquiries and the promotion of meaningful learning by students (Veermans \& Järvelä, 2004). This is particularly true when IBL is undertaken online (Krajcik, Blumenfeld, Marx, \& Soloway, 2000).

Another possible explanation is that most information on European tourism is not presented in Chinese, which can be problematic for students whose native language is not English, given the hindrance posed by the language barrier to the inquiry processes of students (Tapanes, Smith, \& White, 2009; Olaniran, Rodriguez, \& Williams, 2011).

Even so, the relationships between the altered epistemological beliefs and performance on the delayed test were higher $(\gamma=.556)$, since students can engage in complex reasoning and knowledge-constructing tasks to acquire knowledge. This occurs because epistemological beliefs develop or change along with the participation of an individual in instructional or educational practices (Zwaal \& Otting, 2007). Knowledge acquired in this fashion tends to be retained longer by an individual. Future research may shed light on this issue from the human cognition perspective. For example, the Adaptive Control of Thought-Revised (ACT-R) theory of the cognitive information process proposed by Anderson (1996) asserts that learning and cognitive processes are supported by declarative and procedure knowledge. ACT-R explains how complex tasks can be accomplished through the interplay of these two types of knowledge. Being a successful tour leader requires performing complex tasks to provide service. More studies on the application of ACT-R to tourism education can be expected.

An increasing number of tourism training courses are being integrated with web-based technology to accommodate the attributes of Net-Generation learners, who rely heavily on search engines such as Google for information (Oblinger, 2008). Online IBL seems to be an ideal pedagogical technique to help learners develop sophisticated epistemology and subsequently improve their learning outcomes. Specifically, this study posits that online IBL may lead to a change in the epistemological beliefs of tourism students, which was hypothesised to be critical to the formulation of deep learning. Interestingly, yet counter-intuitively, the present research discovered that the changes in the epistemological beliefs of learners did not strongly correlate with improvement in pre- and post-tests on knowledge concerning European tourism. Nevertheless, the administration of a delayed test confirmed a mild association to the epistemological beliefs of individuals after they had experienced online IBL. Such results imply that online IBL triggers changes in epistemological beliefs, and also that appropriate support in technology and/or pedagogy should be granted to the instructor by peers or the administration. A suitable design of the IBL process for better learning outcomes is also suggested by the present study.

Caution is advised when interpreting the results in other contexts due to the following research limitations. The first is the small number of participants, which limits the generalisability of the results. Further, the results of statistical analyses may be distorted because randomisation was not applied in the selection of the participants. A larger and more diverse sample should be used to examine the results of the present study. The research instrument is the second limitation of the present study. The EBS developed by Chan and Sachs (2001) consists of nine items, which may raise questions on its validity. Notwithstanding explanations about why this instrument was adopted by the present study, future research may consider exploiting other inventories to measure participants' epistemological beliefs or further include qualitative 
data to triangulate the data and enhance the validity. Lastly, factors such as motivation and prior knowledge have been proven crucial to the performance of learners (Chan \& Sachs, 2001); therefore, they should be taken into account when measuring learning outcomes.

\section{Conclusion and implications}

In this age of widespread ICT and learners of the Internet generation, whose learning styles are different from those of previous generations, many innovative means of education are widely discussed in academia. In the present study, a tourism training program was designed with the innovative pedagogy of online IBL. To investigate the effects of online IBL on learning the subject of tourism, the present study first examined the changes in epistemological beliefs among participants after they had experienced online IBL. The results of descriptive statistics and paired t-test indicated that the changes were significant, which was confirmed by a large effect size. These results suggest the possible effectiveness of online IBL in helping tourism students' develop more sophisticated epistemological beliefs.

In learning the subject of European tourism, changes in the epistemological beliefs of students had a significant but weak coefficient when the correlation was measured with differences between the pre- and post-tests. However, when the target of measurement was switched to the variables of the changes to epistemological beliefs and the delayed test, the coefficient was higher and more significant. It is sound to argue, therefore, that while online IBL may not be able to help learners comprehend the subject matter immediately, it may facilitate better long-term retention. This situation is interesting and merits further research.

The results of the present study have possible implications for tourism pedagogy and future research. In terms of pedagogical implications, practitioners of tourism training programs may adopt online IBL to help learners cultivate sophisticated epistemological beliefs that are found to be positively related to better learning outcomes. Furthermore, teachers may become aware of learners' level of sophisticated epistemological beliefs and provide assistance accordingly through online IBL. The findings of the present study also have theoretical implications for fellow scholars. The examination of the relationship between the epistemological beliefs and learning strategies of tourism students within the online learning context is still in its infancy. More research should be conducted to yield greater insights that will enrich the body of knowledge pertaining to this area.

\section{Acknowledgements}

This research project was sponsored by National Science Council under the Grant NSC 101-2511-S-328001. The authors would like to dedicate his greatest appreciation to all the people who participated in and contributed to this study as well as anonymous reviewers' constructive comments on earlier version of this manuscript.

\section{References}

Adiele, C., \& Nwanze, E. D. (2010). The dynamics of interactivity modeling for e-learning. Knowledge Management \& E-Learning: An International Journal, 2(4), 370-384.

Anderson, J. R. (1996). ACT: A simple theory of complex cognition. American Psychologist, 51(4), 355365.

Bailey, P. D. (2008). Should 'teacher centered teaching' replace 'student centered learning'? Chemistry Education Research Practice, 9, 70-74.

Barzilai, S., \& Zohar, A. (2012). Epistemic thinking in action: Evaluating and integrating online sources. Cognition and Instruction, 30(1), 39-85. doi: 10.1080/07370008.2011.636495

Bendixen, L. D., \& Hartley, K. (2003). Successful learning with hypermedia: The role of epistemological beliefs and metacognitive awareness. Journal of Educational Computing Research, 28(1), 15-30. 
Bilgin, I. (2009). The effects of guided inquiry instruction incorporating a cooperative learning approach on university students' achievement of acid and bases concepts and attitude toward guided inquiry instruction. Scientific Research and Essay, 4(10), 1038-1046.

Bradshaw, A. C., Bishop, J. L., Gens, L. S., Miller, S. L., \& Rogers, M. A. (2002). The relationship of the World Wide Web to thinking skills. Educational Media International, 39, 275-284.

Bråten, I., \& Strømsø, H. I. (2006). Effects of Personal Epistemology on the Understanding of Multiple Texts. Reading Psychology, 27(5), 457-484. doi: 10.1080/02702710600848031

Bråten, I., Strømsø, H. I., \& Samuelstuen, M. S. (2005). The relationship between internet-specific epistemic beliefs and learning within internet technologies. Journal of Educational Computing Research, 33(2), 141-171.

Briell, J., Elen, J., Depaepe, F., \& Calrebout, G. (2010).The exploration of drawings as a tool to gain entry to students' epistemological beliefs. Electronic Journal of Research in Educational Psychology, $8(2), 655-688$.

Brownlee, J., \& Berthelsen, D. (2008). Developing relational epistemology through relational pedagogy: New ways of thining about personal epistemology in teacher education. In M. S. Khine (Ed.), Knowing, knowledge and beliefs: Epistemological studies across diverse culture (pp. 405-422). Brisbane, Australia: Springer.

Buhalis, D. (2000). Marketing the competitive destination of the future. Tourism Management, 21(1), $97-$ 116. doi:10.1016/S0261-5177(99)00095-3

Cakir, M. (2008). Constructivist approaches to learning in science and their implications for science pedagogy: A literature review. International Journal of Environmental \& Science Education, 3(4), 193-206.

Capraro, R. M., \& Capraro, M. M. (2002). Treatments of effect sizes and statistical significance tests in textbooks. Educational and Psychological Measurement, 62(5), 771-782. doi: 10.1177/001316402236877

Chan, C. K. K., \& Sachs, J. (2001). Beliefs about learning in children's understanding of science texts. Contemporary Educational Psychology, 26(2), 192-210. doi: 10.1006/ceps.1999.1045.

Chan, K. (2003). Hong Kong teacher education students' epistemological beliefs and approaches to learning. Research in Education, 69, 36-50.

Chan, K. (2007). Hong Kong teacher education students epistemological beliefs and their relations with conceptions of learning and learning strategies. The Asia-Pacific Education Researcher 16(2), 199214.

Chan, K., \& Elliot, R. G. (2003). Exploratory study of Hong Kong teacher education students' epistemological beliefs: Cultural perspectives and implications on beliefs research. Contemporary Educational Psychology, 27(3), 392-415.

Chan, N.-M., Ho, I. T., \& Ku, K. Y. L. (2011). Epistemic beliefs and critical thinking of Chinese students. Learning and Individual Differences, 21(1), 67-77. doi: 10.1016/j.lindif.2010.11.001

Chan, Y., -Y, Lam, H., -F., Yang, H. H., Mark, K., -P., \& Leung, C., -H. (2010). Hybrid inquiry-based learning. In F. L. Wang, J. Fong, \& R. C. Kwan (Eds.).Handbook of research on hybrid learning models: Advanced tools, technologies, and applications (pp. 203- 227). New York: Hersey.

Chang, C., -S., Chen, T., -S, \& Hsu, W. -H. (2011). The study on integrating WebQuest with mobile learning environmental education. Computers \& Education, 57, 1228-1239. doi:

10.1016/j.compedu.2010.12.005 
Chen, C. -H., \& Chen, C. -Y. (2012). Instructional approaches on science performance, attitude and inquiry ability in a computer-supported collaborative learning environment. The Turkish Online Journal of Educational Technology, 11(1), 113-122.

Chen, X., \& Choi, J. H. (2010). Designing online collaborative location-aware platform for history learning. Journal of Educational Technology Development and Exchange, 3(1), 13-26.

Cho, Y. H., Lee, J., \& Jonassen, D. H. (2011). The role of tasks and epistemological beliefs in online peer questioning. Computers \& Education, 56(1), 112-126. doi: 10.1016/j.compedu.2010.08.014

Chuang, S. -C., \& Tsai, C. -C. (2005). Preferences toward the constructivist internet-based learning environments among high school students in Taiwan. Computers in Human Behavior, 21, 255-272.

Cohen, J. (1988). Statistical power analysis for the behavioral sciences (2nd ed.). Hillsdale, NJ: Lawrence Erlbaum Associates.

Conley, A. M., Pintrich, P. R., Vekiri, I., \& Harrison, D. (2004). Changes in epistemological beliefs in elementary science students. Contemporary Educational Psychology, 29, 186-204. doi: 10.1016/j.cedpsych.2004.01.044

Cushner, K. H. (2004). Beyond tourism: A practical guide to meaningful educational travel. Lanham: Scarecrow Education, An imprint of the Rowman \& Littlefield Publishing Group, Inc.

Dale, C., \& Lane, A. (2008). A wolf in sheep's clothing? An analysis of student's engagement with virtual learning environments. Journal of Hospitality, Leisure, Sport and Tourism Education, 6(2), 100-108. doi: 10.3794/johlste.62.156

Deniz, H. (2011). Examination of changes in prospective elementary teachers' epistemological beliefs in science and exploration of factors meditating that change. Journal of Science Education and Technology, 20(6), 750-760. doi: 10.1007/s10956-010-9268-x

Duell, O. K., \& Schommer-Aikins, M. (2001). Measures of people's beliefs about knowledge and learning. Educational Psychology Review, 13(4), 419-449.

Edelson, D. C., Gordin, D. N., \& Pea, R. D. (1999). Addressing the challenges of inquiry-based learning through technology and curriculum design. The Journal of the Learning Science, 8(3 \& 4), 391-450.

Elder, A. D. (2002). Characterizing fifth grade students' epistemological beliefs in science. In P. R. Pintrich (Ed.), Personal Epistemology: The psychology of beliefs about knowledge and knowing, (pp. 347-364). Mahwah, NJ, USA: Lawrence Erlbaum associates.

Elby, A., \& Hammer, D. (2001). On the substance of a sophisticated epistemology. Science Education, $85(5), 554-567$.

Fenouillet, F., \& Kaplan, J. (2010).Impact of learning modalities on academic success. European Journal of Open, Distance and E-Learning. Retrieved from http://www.eurodl.org/?article=399.

Garcia, I., Pacheco, C., \& Garcia, G. (2010). A platform of constructivist learning in practice: Computer literacy integrated into elementary school. International Journal of Emerging Technologies in Learning (iJET), 5(2), 15-24. doi: doi:10.3991/ijet.v5i2.1040

Gulati, S. (2004). Constructivism and emerging online learning pedagogy: A decision for formal to acknowledge and promote the informal. In Paper Annual Conference of the Universities Association for Continuing Education-Regional Futures: Formal and Informal Learning Perspectives, Centre for Lifelong Learning, University of Glamorgan UK. 
Hammer, D., \& Elby, A. (2002). On the form of a personal epistemology. In B. K. Hofer \& P. R. Pintrich (Eds.), Personal epistemology: The psychology of beliefs about knowledge and knowing. Mahwah: NJ: Erlbaum.

Harteis, C., Gruber, H., \& Hertramph, H. (2010). How epistmic beliefs influence e-Learning in daily work-life. Educational Technology \& Society, 13(3), 201-211.

Hakkarainen, K. (2003). Emergence of progressive inquiry culture in computer-supported collaborative learning. Learning Environments Research, 6(2), 199-220.

Hassanien, A. (2006). Using Webquest to support learning with technology in higher education. Journal of Hospitality, Leisure, Sport and Tourism Education, 5(1), 41-49. doi: 10.3794/johlste.51.96

Hickey, D. T., Wolfe, E. W., \& Kindfield, A. C. H. (2000). Assessing learning in a technology-supported genetics environment: Evidential and consequential validity issues. Educational Assessment, 6, 155196.

Hmelo-Silver, C. E., Duncan, R. G., \& Chin, C. A. (2007). Scaffolding and achievement in problembased and inquiry learning: A response to Kirschner, Sweller, and Clark (2006). Educational Psychologist 42(2), 99-107.

Hofer, B. K. (2001). Personal epistemology research: Implications for learning and teaching. Journal of Educational Psychology Review, 13(4), 353-383. doi: 10.1023/A:1011965830686

Hofer, B. K. (2004). Introduction: Paradigmatic approaches to personal epistemology. Educational Psychologist, 39(1), 1-3. doi: 10.1207/s15326985ep3901_1

Hofstein, A., \& Lunetta, V. N. (2004). The laboratory in science education: Foundations for the twentyfirst century. Science Education, 88, 28-54.

Ikpeze, C. H., \& Boyd, F. B. (2007). Web-based inquiry learning: Facilitating thoughtful literacy with WebQuests. The Reading Teacher, 60(7), 644-654. doi: 10.1598/RT.60.7.5

Inui, Y., Wheeler, D., \& Lankford, S. (2006). Rethinking tourism education: What should schools teach? Journal of Hospitality, Leisure, Sport and Tourism Education, 5(2), 25-35. doi: $10.3794 /$ johlste.52.122

Jordan, F. (2005). Teaching and research. In D. Airey \& J. Tribe (Eds.), An international handbook of tourism education (pp. 469-482). Oxford: Elsevier Ltd.

Kasli, M., \& Avcikurt, C. (2008). An investigation to evaluate the websites of tourism departments of universities in Turkey. Journal of Hospitality, Leisure, Sport and Tourism Education, 7(2), 77-92. doi: 10.3794/johlste.72.194.2005.01.001

Kienhues, D., \& Bromme, R. (2011). Beliefs about abilities and epistemic beliefs: Aspects of cognitive flexibility in information-rich environments links between beliefs and cognitive flexibility. In J. Elen, E. Stahl, R. Bromme and G. Clarebout (Eds.), Links between beliefs and cognitive flexibility: lessons learned (pp. 105-124). New York: Springer. doi:10.1007/978-94-007-1793-0_6

King, P., \& Kitchener, K. (2004). Reflective judgement: Theory and research on the development of epistemic assumptions through adulthood. Educational Psychologist, 39(1), 5-18.

Kirk, R. E. (2001). Promoting good statistical practices: Some suggestions. Educational and Psychological Measurement, 61, 13-218.

Kizilgunes, B., Tekkaya, C., \& Sungur, S. (2009). Modeling the relations among students' epistemological beliefs, motivation, learning approach, and achievement. The Journal of Educational Research, 102(4), 243-256. doi: 10.3200/JOER.102.4.243-256 
Kotrlik, J. W., \& Williams, H. A. (2003). The incorporation of effect size in information technology, learning, and performance research. Information Technology, Learning, and Performance Journal, 21(1), 1-7.

Krajcik, J., Blumenfeld, P., Marx, R., \& Soloway, E. (2000). Instructional, curricular, and technological supports for inquiry in science classroom. In J. Minstrell \& E. H. van Zee (Eds.), Inquiring into inquiry learning and teaching in science. Washington: American Association for the Advancement of Science.

Kuhn, D., \& Udell, W. (2001). The path to wisdom. Educational Psychologist, 36(4), 261-264.

Lakkala, M., Lallimo, J., \& Hakkarainen, K. (2005). Teachers' pedagogical designs for technologysupported collective inquiry: A national case study. Computers \& Education, 45, 337-356. doi: 10.1016/j.compedu.2005.04.010

Lane, J. L. (2007). Inquiry-based learning. Retrieved from http://www.schreyerinstitute.psu.edu/pdf/IBL.pdf

Leung, Y. -F., \& Ivy, M. I. (2003) How useful are course websites? A study of students' perceptions. Journal of Hospitality, Leisure, Sport and Tourism Education, 2(2), 15-25. doi: 10.3794/johlste.22.38

Li, D. D., \& Lim, C. P. (2008). Scaffolding online historical inquiry tasks: A case study of two secondary school classrooms. Computers \& Education, 50(4), 1394-1410.

Lim, B. -R. (2004). Challenges and issues in designing inquiry on the Web. British Journal of Educational Technology, 35(5), 627-643. doi: 10.1111/j.0007-1013.2004.00419.x

Lin, X. (2001). Designing metacognitive activities. Educational Technology Research \& Development, 49(2), 23-40.

Liu, C. H., \& Matthews, R. (2005). Vygotsky's philosophy: Constructivism and its criticisms examined. International Education Journal, 6(3), 386-399.

Liu, P. -H., \& Liu, S. -Y. (2011). A cross-subject investigation of college students' epistemological beliefs of Physics and Mathematics. The Asia-Pacific Education Researcher, 20(2), 336-351.

Liu, C. H., \& Matthews, R. (2005). Vygotsky's philosophy: Constructivism and its criticisms examined. International Education Journal, 6(3), 386-399.

Lodewyk, K. R. (2007). Relations among epistemological beliefs, academic achievement, and task performance in secondary school students. Educational Psychology, 27, 307-327.

Lynch, S., Kuipers, J., Pyke, C., \& Szesze, M. (2005). Examining the effects of a highly rated science curriculum unit on diverse students: Results from a planning grant. Journal of Research in Science Teaching, 42, 921-946.

Malaki, A. M. S. (2009). Asian values and epistemological beliefs as predictors of valuing education. The International Journal of Research and Review, 1, 1-36.

Manlove, S., Lazonder, A. W., \& Jong de, T. (2009). Trends and issues of regulative support use during inquiry learning: Patterns from three studies. Computers in Human Behavior, 25(4), 795-803.

Mason, L., Boldrin, A., \& Ariasi, N. (2010). Epistemic metacognition in context: Evaluating and learning online information. Cognition and Instruction, 5(1), 67-90.

McLoughlin, C., \& Lee, M. J. W. (2008). The three P's of pedagogy for the networked society personalization. International Journal of Teaching and Learning in Higher Education, 20(1), 10-27. 
Minick, T., \& Bocchicchio, V. (2006). An honors pilot course: Cross-cultural service and inquiry-based learning in Mérida, Mexico. National Collegiate Honors Council Honors in Practice-Online Archive. Retrieved from http://digitalcommons.unl.edu/nchchip/7.

Miller, M. T., \& Lu, M. -Y. (2003). Serving non-traditional students in e-learning environments: Building successful communities in the virtual campus. Educational Media International, 40(1-2), 163-169.

Muis, K. R. (2007). The role of epistemic beliefs in self-regulated learning. Educational Psychologist, 42(3), 173-190. doi: 10.1080/00461520701416306

Munar, A. M., \& Montaño, J. J. (2009). Generic competences and tourism graduates. Journal of Hospitality, Leisure, Sport \& Tourism Education, 8(1), 70-84. doi: 10.3794/johlste.81.206

Nakagawa, S., \& Cuthill, I. C. (2007). Effect size, confidence interval and statistical significance: a practical guide for biologists. Biological Reviews, 82(4), 591-605. doi: 10.1111/j.1469185X.2007.00027.x

O’Siochru, C., \& Norton, L. (2013). Epistemic match: a pedagogical concept for understanding how students fit into the chosen subject. Innovations in Education and Teaching International, 1-12. doi: $10.1080 / 14703297.2013 .774138$

Oblinger, D. (2008). Growing up with google - What it means to education? Emerging Technologies for Learning, 3, 11-29.

Olaniran, B. A., Rodriguez, N. B., \& Williams, I. M. (2011).Cross-cultural challenges in web-based instruction. Knowledge Management \& E-Learning: An International Journal, 2(4), 448-465.

Olejnik, S., \& Algina, J. (2000). Measures of effect size for comparative studies: Applications, interpretations, and limitations. Contemporary Educational Psychology, 25, 241-286.

Oliver, R. (2007). Exploring an inquiry-based learning approach with first-year students in a large undergraduate class. Innovations in Education and Teaching International, 44(1), 3-15. doi: $10.1080 / 14703290601090317$

Paavola, S., Lipponen, L., \& Hakkarainen, K. (2002). Epistemological foundations for CSCL: A comparison of three models of innovative knowledge communities. In G. Stahl (Ed.), Computer support for collaborative learning: Foundations for a CSCL community. Hillsdale: Erlbaum.

Paganelli, F., Bianchi, G., \& Melani, V. (2006). A context-aware e-Tourism application enabling collaboration and knowledge exchange among tourists. In P. Cunningham \& M. Cunningham (Eds.), Exploiting the knowledge economy: Issues, applications, case studies. Retrieved from http://radar.det.unifi.it/people/Paganelli/publications/eChallenges_e2006_kamer.pdf.

Peng, H., \& Fitzgerald, G. (2006). Relationships between teacher education students' epistemological beliefs and their learning outcomes in a case based hypermedia learning environment. Journal of Technology and Teacher Education, 14, 255-285.

Peterson, M. (2006). Learner interaction management in an avatar and chat-based virtual world. Computer Assisted Language Learning, 19(1), 79-103. doi: 10.1080/09588220600804087

Pieschl, S., Stahl, E., \& Bromme, R. (2008). Epistemological beliefs and self-regulated learning with hypertext. Metacognition Learning, 3, 17-37.

Pintrich, P. R. (2002). Future challenges and directions for theory and research on personal epistemology. In P. R. Pintrich (Ed.), Personal epistemology: The psychology of beliefs about knowledge and knowing (pp. 389-414). Mahwah, NJ, USA: Lawrence Erlbaum Associates. 
Prince, M. J., \& Felder, R. M. (2006). Inductive teaching and learning method: Definitions, comparisons and research bases. Journal of Engineering Education, 95(2), 123-138.

Rodríguez, L., \& Cano, F. (2006). The epistemological beliefs, learning approaches and study orchestrations of university students. Studies in Higher Education, 31(5), 617-636. doi: $10.1080 / 03075070600923442$

Rogers, Y., \& Price, S. (2009). How mobile technologies are changing the way children learn. In A. Druin, (Ed.) On the Move: Children, Learning and Technology (pp. 3-22). Boston: Morgan Kaufmann. Retrieved from http://mcs.open.ac.uk/yr258/papers/Rogers_Price09chapter.pdf

Rogers, D. \& Swan, K. (2004). Self-regulated learning and internet searching. Teachers College Record, 106(9), 1804-1824.

Rop, C. F. (2002). The meaning of student inquiry questions: A teacher's beliefs and responses. International Journal of Science Education, 24, 717-736.

Rozendaal, J. S., Brabander, d., C. J., \& Minnaert, A. (2001). Bounderies and dimensionality of epistemological beliefs. In the biennial meeting of the European Association for Research on Learning and Instruction, Fribourg, Switzerland.

Sahin, Y. G., Balta, S. \& Ercan, T. (2010). The use of internet resources by university students during their course projects elicitation: A case study. The Turkish Online Journal of Educational Technology, $9(2), 234-244$.

Savery, J. R., \& Duffy, T. M. (2001). Problem Based Learning: An Instructional Model and Its Constructivist Framework (CRLT Technical Report No. 16-01). Bloomington, IN: Indiana University. Retrieved from http://java.cs.vt.edu/public/classes/communities/readings/Savery-DuffyConstructivePBL.pdf

Scarlatos, L. L. (2006). Tangible math. International Journal of Interactive Technology and Smart Education, Special Issues on Computer Game-Based Learning, 3(4), 293-309.

Schommer-Aikins, M. (2004). Explaining the epistemological belief system: Introducing the embedded systemic model and coordinated research approach. Educational Psychologist, 39(1), 19-29. doi: $10.1207 / \mathrm{s} 15326985$ ep3901_3

Schommer-Aikins, M., Duell, O. K., \& Barker, S. (2003). Epistemological beliefs across domains using Biglan's classification of academic disciplines. Research in Higher Education, 44, 347-366.

Schommer-Aikins, M., Duell, O. K., \& Hutter, R. (2005). Epistemological beliefs, mathematical problem solving beliefs, and academic performance of middle school students. Elementary School Journal, 105, 289-304.

Schraw, G., Bendixen, L. D., \& Dunkle, M. E. (2002). Development and validation of the Epistemic Belief Inventory (EBI). In B. K. Hofer \& P. R. Pintrich (Eds.), Personal epistemology. The psychology of beliefs about knowledge and knowing (pp. 261-275). Mahwah: Erlbaum.

Schraw, G., \& Sinatra, G. M. (2004).Epistemological development and its impact on cognition in academic domains. Contemporary Educational Psychology, 29, 95-102.

Shih, J. -L., Chuang, C. -W., \& Hwang, G., -J. (2010). An inquiry-based mobile learning approach to enhancing social science learning effectiveness. Educational Technology and Society, 13(4), 50-62.

Sigala, M. (2002). The evolution of internet pedagogy: Benefits for tourism and hospitality education. Journal of Hospitality, Leisure, Sport and Tourism Education, 1(2), 29-45. doi: 10.3794/johlste.12.4 
Slotta, J. D. (2002). Designing the web-based inquiry science environment. Educational Technology, $42(5), 15-20$.

Strickland, J. (2005). Using Webquests to teach content: Comparing instructional strategies. Contemporary Issues in Technology and Teacher Education, 5(2), 138-148.

Tan, C., \& Chan, Y., -Y. (2008). Knowledge community: A knowledge-building system for global collaborative project learning. Proceedings of the IEEE, 96(6), 1049-1061. doi: 10.1109/JPROC.2008.921608

Tapanes, M. A., Smith, G. G., \& White, J. A. (2009). Cultural diversity in online learning: A study of the perceived effects of dissonance in levels of individualism/collectivism and tolerance of ambiguity. Internet and Higher Education, 12(1), 26-34.

Teo, T., \& Chai, C. S. (2011). Confirmatory factor analysis of the epistemic belief inventory (EBI): A cross-cultural study. The International Journal of Educational and Psychological Assessment, 9(1), 113.

Tribe, J. (2001). Research paradigms and the tourism curriculum. Journal of Travel Research, 39, 442448.

Thompson, B. (2002). What future quantitative social science research could look like: Confidence intervals for effect sizes. Educational Researcher, 31(3), 25-32.

Tsai, C. -C. (2008). The preferences toward constructivist Internet-based learning environments among university students in Taiwan. Computers in Human Behavior, 24(1), 16-31.

Tsai, C. -C. (2012). The development of epistemic relativism versus social relativism via online peer assessment, and their relations with epistemological beliefs and internet self-efficacy. Educational Technology \& Society, 15(2), 309-316.

Tsai, C. -C. \& Chuang, S. C. (2005).The correlation between epistemological beliefs and preferences toward Internet-based learning environments. British Journal of Educational Technology, 36(1), 97 100.

Tsai, P. -S., Tsai, C. -C., \& Hwang, G., -H. (2011a). The correlates of Taiwan teachers; epistemological beliefs concerning Internet environments, online search strategies, and search outcomes. Internet and Higher Education, 14, 54-63.doi:10.1016/j.iheduc.2010.03.003.

Tsai, P. -S., Tsai, C. -C., \& Hwang, G., -H. (2011b). College students' conceptions of context-aware ubiquitous learning: A phenomenographic analysis. Internet and Higher Education, 14, 137-141. doi:10.1016/j.iheduc.2011.01.004

Tu, Y. -W., Shih, M., \& Tsai, C. -C. (2008). Eighth graders' web searching strategies and outcomes: The role of task types, web experiences and epistemological beliefs. Computers \& Education, 51(3), 11421153. doi: 10.1016/j.compedu.2007.11.003

Valanides, N., \& Angeli, C. (2005). Effects of instruction on changes in epistemological beliefs. Contemporary Educational Psychology, 30, 314-330. doi: 10.1016/j.cedpsych.2005.01.001

Van Fossen, P. J. (2004). Using WebQuests to scaffold higher-order thinking. Social Studies and the Young Learner, 16(4), 13-16.

Veermans, M., \& Järvelä, S. (2004).Generalized achievement goals and situational coping in inquiry learning. Instructional Science, 32(4), 269-291.

Vygotsky, L. S. (1978). Mind in society: The development of higher psychological processes. Cambridge, MA: Harvard University Press. 
Wegner, S. B., Holloway, K. C., \& Garton, E. M. (1999). The effects of internet-based instruction on student learning. Journal of Asynchronous Learning Networks, 3(2), 98-106.

Whitmire, E. (2003). Epistemological beliefs and the information-seeking behavior of undergraduates. Library \& Information Science Research, 25, 127-142. doi: 10.1016/S0740-8188(03)00003-3

Whitmire, E. (2004). The relationship between undergraduates' epistemological belief, reflective judgements, and their information-seeking behavior. Information Processing Management, 40, 97-111.

Wu, H. K., \& Hsieh, C. E. (2006). Developing sixth graders' inquiry skills to construct explanations in inquiry-based learning environments. International Journal of Science Education, 28(11), 1289-1313. doi: $10.1080 / 09500690600621035$

Youn, I. (2000). The culture specificity of epistemological beliefs about learning. Asian Journal of Social Psychology, 3, 87-105.

Zwaal, W., \& Otting, H. (2006). Hospitality management students' conceptions of education. Tourism and Hospitality Research, 7(3/4), 256-268. doi: 10.1057/palgrave.thr.6050048

Corresponding author: Liwei Hsu, liweihsu@mail.nkuht.edu.tw

Australasian Journal of Educational Technology (C) 2014.

Please cite as: Hsu, L. (2014). An epistemological analysis of the application of an online inquiry-based program in tourism education. Australasian Journal of Educational Technology, 30(1), 61-79. 